\title{
Antisemitismo, racismo y tercermundismo en Tacuara y sus agrupaciones derivadas (1959-1965)
}

\author{
(-) Esteban Javier Campos ${ }^{1}$ \\ Instituto de Historia Argentina y Americana Dr. "Emilio Ravignani-Universidad de Buenos Aires/ \\ Conicet, Argentina. \\ Correo electrónico: estebancampos1977@gmail.com
}

Fecha de recepción: 16 de julio de 2020 Fecha de aceptación: 10 de diciembre de 2020

\section{Resumen}

El propósito de este artículo es analizar el discurso sobre las razas en Tacuara y sus agrupaciones derivadas, en el contexto de las mutaciones transnacionales del racismo luego de la posguerra. En la primera parte del trabajo, se investigan las figuras del antisemitismo en el Movimiento Nacionalista Tacuara (MNT), el Movimiento Nueva Argentina (MNA) y el Movimiento Nacionalista Revolucionario Tacuara (MNRT), con posturas sobre la "cuestión judía" que oscilaron entre el racismo biológico, el racismo culturalista, el antisionismo y la crítica a la discriminación racial. En la segunda parte, se estudia la recepción de las categorías de raza, clase y tercer mundo en las dos fracciones que dividieron al MNRT. Para desarrollar estos argumentos, se examina la prensa política de estas organizaciones, como el periódico Tacuara. Vocero de la juventud nacionalista, el boletín Ofensiva, Barricada del nacionalismo revolucionario, Tacuara del manchón y Nueva Argentina. A la muestra se suman otros documentos provenientes de la Dirección de Inteligencia de la Policía de la Provincia de Buenos Aires (DIPBA), una entrevista al MNA de la revista Vea y Lea, semanarios como Primera Plana, Panorama y Mundo israelita. 


\title{
Antisemitism, Racism and Third Worldism in Tacuaria and its Derived Groups (1959-1965)
}

\begin{abstract}
The purpose of this article is to analyze the discourse on race in Tacuara and its derived groupings, in the context of the transnational mutations of racism after the second post-war period. In the first part of the paper, we investigated the figures of anti-Semitism in the Movimiento Nacionalista Tacuara (MNT), the Movimiento Nueva Argentina (MNA) and the Movimiento Nacionalista Revolucionario Tacuara (MNRT), with positions on the "Jewish question" that oscillated between biological racism, culturalist racism, anti-Zionism and criticism of racial discrimination. In the second part, we study the reception of the categories of race, class and third world in the two fractions that divided the MNRT. To develop these arguments, we examine the political press of these organizations, such as Tacuara. Vocero de la juventud nacionalista, the bulletin Ofensiva, Barricada del nacionalismo revolucionario, Tacuara del manchón and Nueva Argentina. The sample is supplemented by other documents from the Direction of Intelligence of the Police of the Province of Buenos Aires (DIPBA), an interview with MNA from Vea y Lea magazine, weeklies such as Primera Plana, Panorama and Mundo Israelita.
\end{abstract}

Keywords: Biological Racism, Culturalist Racism, Anti-Semitism, Third World.

A lo largo del siglo XX, el antisemitismo fue una presencia latente y constante en la sociedad argentina, con diversos episodios de violencia. Desde 1959, el activismo contra personas e instituciones vinculadas a la comunidad judía experimentó una curva ascendente, que alcanzó su punto más elevado entre 1960 y 1962 con una ola de atentados (Gutman, 2003: 124-125, Padrón, 2012: 40 y Senkman, 1989: 11-108). Los medios de prensa y los servicios de inteligencia se hicieron eco de varios de estos hechos: en julio de 1960, el Correo de la tarde informaba de un acto realizado en Plaza Once por la Unión Cívica Nacionalista, que terminó con incidentes en la desconcentración. En el mitin "abundaron expresiones hostiles a los judíos, el capitalismo y la democracia”; luego los participantes marcharon por la Avenida Rivadavia “entonando diversos estribillos”, pero la policía intervino y se produjeron algunas detenciones. ${ }^{2}$ En enero de 1962, se realizó en Tandil una serie de allanamientos a una célula que respondía al Movimiento Nacionalista Tacuara (MNT), donde se encontraron explosivos, un mimeógrafo y varios objetos con simbología nazi. Este grupo, encabezado por el delegado metalúrgico Juan Carlos Schmidt, el dirigente de la Unión Republicana Alfredo Ricardo Manera y otros activistas, había colocado una bomba en el cine Cervantes mientras se proyectaba la película Cenizas sin gloria, que retrataba la vida íntima de Adolf

2 (26 de julio de 1960). Incidentes en Plaza Once: detenciones, Correo de la tarde. Comisión Provincial por la Memoria, Archivo de la DIPBA (en adelante CPM-DIPBA), Colección 2 "Movimiento Nacionalista Tacuara (1962-1976)", folio n. 187. La Unión Cívica Nacionalista fue una pequeña agrupación con personería jurídica que se asoció al MNT, permitiéndole a esta última usar su local y presentarse a elecciones. 
Hitler. De acuerdo con los reportes de inteligencia, los detenidos celebraron una reunión donde habrían propuesto a sus camaradas "darles un susto a los judíos" que verían el film. ${ }^{3}$ En julio, la Liga por los Derechos del Hombre No Judío realizó una pegatina de afiches de contenido antisemita en Quilmes. Los pasquines acusaban a "consorcios judíos internacionales" por la dependencia económica del país, y a "comandos judíos" por violar la soberanía nacional, en clara alusión al secuestro por el servicio secreto israelí del criminal de guerra nazi Adolf Eichmann en San Fernando, dos años atrás. ${ }^{4}$ En octubre, tres jóvenes pertenecientes al Frente Revolucionario Nacionalista arrojaron una bomba molotov contra una sinagoga de Vicente López y realizaron disparos con una escopeta de perdigones, que provocaron heridas leves a dos niñas que jugaban en la calle. ${ }^{5}$

Los casos más resonantes, sin embargo, tuvieron como escenario a la ciudad de Buenos Aires. El primero ocurrió en junio de 1962, a pocas semanas de la ejecución de Eichmann en Jerusalén, cuando la estudiante Graciela Sirota denunció a grupos antisemitas por haberla secuestrado y marcado con una navaja una cruz esvástica en el pecho. El segundo fue el asesinato de Raúl Alterman en 1964, que fue baleado en su domicilio como venganza por la muerte de tres miembros del MNT en un enfrentamiento con militantes del Partido Comunista en Rosario. Los padres de la víctima recibieron una carta que decía: "Nadie mata porque sí nomás; a su hijo lo han matado porque era un sucio judío" (Bardini, 2002: 55-56, Gluck, 2012:59-73, Gutman, 2003: 215-224). La ola de violencia antisemita se produjo en medio de una fuerte inestabilidad política y económica (Senkman, 1989: 14-22). Los signos más visibles de estas derivas eran la recesión generada por el plan de estabilización, la creciente agitación obrera y el nerviosismo militar ante la hipótesis de un peronismo contestatario, a la vez que exitoso en las performances electorales. En este contexto, para la extrema derecha la comunidad judía era parte del bloque de poder que encabezaba el presidente Arturo Frondizi. Ambos serían responsables por entregar la soberanía del país al Estado de Israel a causa del caso Eichmann, al capital extranjero por la apertura del mercado petrolero, y al comunismo internacional debido a las filiaciones izquierdistas atribuidas a los judíos y al primer mandatario. Los motivos del antisemitismo clásico, que asociaban a los judíos con el dinero y la especulación, se desplegaban en una coyuntura modelada por los equilibrios geopolíticos de la Guerra Fría, la proscripción del peronismo y la expansión de la nueva izquierda.

Este artículo se propone analizar las variaciones del discurso sobre las razas en Tacuara y sus agrupaciones derivadas, tomando como punto de referencia las mutaciones transnacionales del racismo a partir de la década de 1960. Con

3 (23 de enero de 1962), Descubren ramificaciones de Tacuara en Tandil. Arrestos, Correo de la tarde; (12 de septiembre de 1963), Condenan a 'Tacuaras' que cometieron desmanes en Tandil, Olavarría y Azul, El imperial; "Día 12/12 hallose artefacto explosivo sin explotar en cine 'Cervantes' sito en calle Rodríguez n. 551, Tandil, 13/12/1962". CPM-DIPBA, Colección 2 "Movimiento Nacionalista Tacuara (1962-1976)", folios 117-128.

4 CPM-DIPBA, Colección 2 “Movimiento Nacionalista Tacuara (1962-1976)”, Expediente “D” n. 218, folios n. 86-89.

5 CPM-DIPBA, Colección 2 “Movimiento Nacionalista Tacuara (1962-1976)”, S.I.P.B.A., "Día 27/10 autores ignorados arrojaron bomba 'Molotov' contra templo israelita sinagoga ubicado en calle Caseros n. 1450 y posteriormente efectuaron disparo armas de fuego" (sic), folios n. 90-113. 
el fin de la Segunda Guerra Mundial, el antisemitismo entró en declive en buena parte del planeta (Traverso, 2014: 147-172). Esta trayectoria no fue lineal, ya que el racismo y la judeofobia cambiaron de forma y se adaptaron a una nueva coyuntura, signada por el auge de la descolonización, los movimientos de población de la periferia a los países centrales, y la consolidación del Estado de Israel. En este contexto, el clásico racismo biológico, cientificista, universalista y heterófobo, transitó hacia un nuevo racismo culturalista, diferencialista y heterófilo, que sustituyó la jerárquica "ciencia de las razas" por la reivindicación de la singularidad cultural (Taguieff, 1998: 1-14 y Wieviorka, 2007: 13-23). El MNT, en sintonía con esta metamorfosis de carácter global, tenía un discurso que se encontraba a mitad de camino entre el racismo biológico o racialista y el racismo culturalista, entre el antisemitismo y el antisionismo. De allí pues que la construcción de la "cuestión judía" en Tacuara fuera sumamente compleja y variara según el auditorio, ya fuera éste la opinión pública o los ámbitos más reservados de la militancia nacionalista. Las rupturas que sufrió la Tacuara originaria, como el Movimiento Nueva Argentina (MNA) y el Movimiento Nacionalista Revolucionario Tacuara (MNRT), se diferenciaron en sus modos de procesar el antisemitismo y la cuestión racial, con manifestaciones que oscilaron entre la continuidad, la marginación y la crítica abierta de los tópicos racistas. Para desarrollar estos argumentos se examinará la prensa política del MNT, como el periódico Tacuara. Vocero de la juventud nacionalista y el boletín Ofensiva, las publicaciones del MNRT Barricada del nacionalismo revolucionario y Tacuara del manchón, una entrevista al MNA y su prensa oficial, Nueva Argentina. A esta muestra se sumarán otros documentos provenientes de la Dirección de Inteligencia de la Policía de la Provincia de Buenos Aires (DIPBA), revistas como Primera Plana, Panorama y Mundo israelita.

Tacuara fue una organización nacionalista que logró una importante exposición pública por sus prácticas antisemitas, en un contexto de radicalización de la derecha anticomunista en América Latina (Herrán Ávila, 2015: 1-26, Bohoslavsky y Bertonha, 2016; Patto de Sá Motta, 2019). Sus orígenes se remontan a un puñado de militantes provenientes de la Unión Nacionalista de Estudiantes Secundarios que integraron comandos civiles en el golpe militar que derrocó a Juan Domingo Perón. La ideología del MNT encontraba sus principales referencias en la derecha argentina y europea de entreguerras: el falangismo de José Antonio Primo de Rivera, el nacional-sindicalismo de Ramiro Ledesma Ramos, el revisionismo histórico, el antisemitismo católico del padre Julio Meinvielle, y el comunitarismo de Jacques-Marie de Mahieu. A partir de la intervención en el conflicto conocido como laica o libre a favor de la legalización de las universidades privadas, el MNT creció en número y amplió su composición social. El núcleo originario, vinculado a jóvenes de familias patricias que predicaban un nacionalismo de tintes hispanistas y católicos, fue desbordado por la llegada de nuevos militantes de perfil plebeyo y afinidades peronistas, lo que terminó por fracturar la organización. En octubre de 1960, un grupo cercano a Meinvielle -autor de ensayos como El judío en el misterio de la historia y Los tres pueblos bíblicos en su lucha por la dominación del mundo-rompió con el MNT para fundar la Guardia Restauradora Nacionalista, denunciando que Tacuara había sido conquistada por el fidelismo, el trotskismo 
y el ateísmo. ${ }^{6}$ En junio de 1961, siete activistas liderados por Dardo Cabo, hijo del dirigente de la CGT Armando Cabo, rompieron con la dirección tacuarista para crear el MNA, que se identificó con el peronismo, el anticomunismo y el antisionismo.

En el último tercio de 1962 se consumó la ruptura del MNRT, a partir de un grupo liderado por José Luis Nell, Joe Baxter y Alfredo Ossorio, que se definía peronista, reivindicaba un socialismo nacionalista y se organizó clandestinamente para la lucha armada. Varios meses después, Ossorio y sus seguidores se distanciaron al percibir un giro a la izquierda del sector encabezado por Baxter, que había renegado públicamente del antisemitismo y tenía contactos con marxistas como Ismael Viñas, Ricardo Rojo y Mario Valotta (Gutman, 2003: 155-156). El MNRT dirigido por Ossorio se agrupó en torno al periódico Barricada del nacionalismo revolucionario, que conservó algunos tópicos racialistas con un discurso próximo a las ideas de De Mahieu, mientras que el grupo conducido por Baxter y Nell publicó su propio órgano de prensa, conocido como Tacuara del manchón. En agosto de 1963, un comando de este sector asaltó el Policlínico Bancario del barrio de Caballito con un saldo de dos muertos, tres heridos y un botín equivalente a 100.000 dólares, pero la investigación policial llevó a una ola de arrestos que disolvió la agrupación. En la cárcel, varios tacuaristas como Jorge Caffatti, Carlos Arbelos y Alfredo Roca se acercaron al marxismo, para luego continuar su militancia en las Fuerzas Armadas Peronistas. Baxter nunca fue capturado y se convirtió en un activista internacional que visitó a Perón en Madrid y recorrió varios países del tercer mundo hasta recalar en el PRT-ERP. Nell protagonizó una escandalosa fuga de Tribunales, militó con el MLN-Tupamaros en Uruguay y, más tarde, se incorporó a Montoneros.

\section{Antisemitismo, política y biología}

El antisemitismo de Tacuara ha recibido una importante atención por parte de la historiografía y el periodismo, que lo han señalado como uno de los componentes originarios, cuando no fundamentales, en la ideología de la organización nacionalista (Finkelstein, 2016: 151-159, Galvan, 2013: 1-19, Gutman, 2003, Lvovich, 2009: 45-61, Senkman, 2001:277-283). En los relatos testimoniales, en cambio, el tópico es negado o se lo considera un pecado de juventud, equilibrado por la conversión de un puñado de ex tacuaristas a la militancia revolucionaria de los años setenta (Bardini, 2002: 157-158, Gasparini, 2006: 17, Orlandini, 2008: 104-105). ¿Qué lugar ocupaba la "cuestión judía” en el MNT? Un primer acercamiento puede realizarse a través del discurso de Tacuara en reportajes, volantes y panfletos, que intentaban justificar sus posiciones frente a una opinión pública hostil, en medio del auge de la violencia contra la comunidad judía. En mayo de 1962, el periodista Arie Zafran entrevistó a Alberto Ezcurra Uriburu y Joe Baxter para la revista Mundo

6 Archivo de Gabriel Rot (en adelante AGR). (08 de abril de 1972), Joe Baxter: Del Movimiento Tacuara a la guerrilla urbana, Panorama, año 9, n. 258, p. 15. 
Israelita.Interrogado sobre el pensamiento del dirigente fascista británico Oswald Mosley, Baxter respondió:

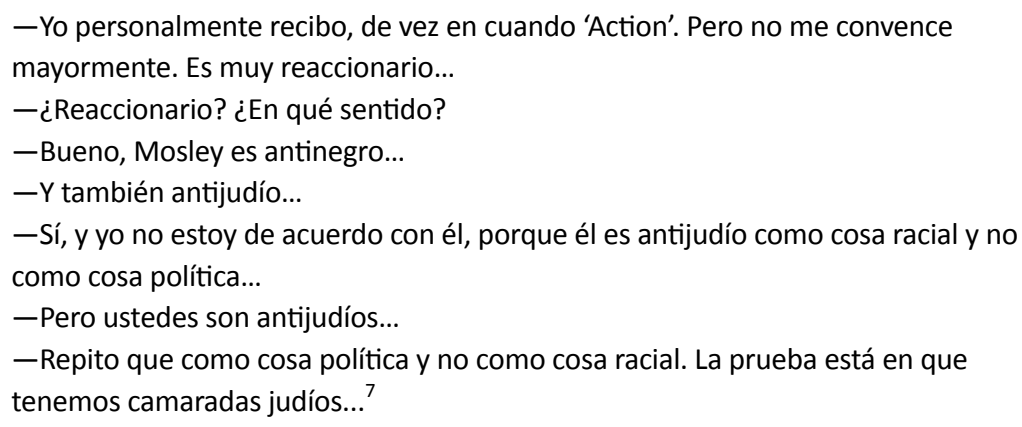

Si seguimos al pie de la letra las palabras de Baxter, el antisemitismo de la dirección tacuarista era de orden político-cultural y no racial. En la misma entrevista, Ezcurra Uriburu daba mayores precisiones al respecto:

No concebimos a la Nación como una unidad racial. Consideramos que la mayoría de la comunidad judía de la Argentina, y principalmente sus agrupaciones representativas, no están adaptadas. No hacemos discriminación en ese sentido. Combatimos igualmente al ciudadano que, siendo argentino, está al servicio de un estado extranjero, ya sea Rusia, Inglaterra, Estados Unidos o Israel. No admitimos la doble nacionalidad y el sionismo es una especie de doble nacionalidad. ${ }^{8}$

Aquí no interesa tanto descifrar algún sentido oculto que se escondería detrás del discurso, sino detectar el significado de los actos del habla, o como decía John Austin, de cómo se hacen cosas con palabras (Skinner, 2007: 185-223). La dignidad política que reclamaba el antisemitismo de Tacuara era una práctica de legitimación que renegaba del racismo para adaptarse a un auditorio específico. Y esto ocurría porque para la opinión pública, aquel antisemitismo con pretensiones científicas, predominante entre fines del siglo XIX y la primera mitad del siglo XX, ya no estaba dentro de los márgenes de lo decible. De acuerdo a Pierre-André Taguieff, con la derrota del nazismo el racismo se convirtió en una práctica de "manifestaciones inconfesables y vergonzosas, por lo tanto, sus expresiones se han hecho indirectas e implícitas" (Taguieff, [1998] 2001:5). Un volante del MNT hallado por los servicios de inteligencia bonaerenses hacia 1964 en la localidad de Médanos, permite reconstruir el contexto intelectual de los argumentos presentados por Tacuara al público:

Tacuara no es un capricho juvenil. No es un club, ni una "Banda de asesinos" que mata judíos y tiran tiros como los diarios nos hacen aparecer (...) No somos racistas. En primer lugar, porque los argentinos no pertenecemos a ninguna raza en especial, y en segundo lugar porque si lo fuéramos, sentiríamos desprecio por las otras razas que componen la humanidad: Árabes, Japoneses, Negros, Indígenas, etc. hacia los cuales nos inclinamos respetuosamente 
(...) Se nos acusa de racistas por una razón de propaganda que el judaísmo emprende para engañar a la opinión y hacernos odiables. Nuestra conducta hacia ellos obedece a que el judaísmo ha inspirado en la historia y en la humanidad todos los males que aquejan a la sociedad humana: Comunismo, Capitalismo, Usura...

El pasaje confirma la existencia de una batalla por la identidad tacuarista, que se definía a partir de la imagen que la agrupación tenía de sí misma, pero también era condicionada por los discursos que la interpelaban desde afuera. Tomadas en su conjunto, estas declaraciones expresan las mutaciones del racismo global que empezaban a operarse en los años sesenta. Tacuara no predicaba un discurso de las jerarquías raciales, pero defendía los presupuestos universalistas (que sacralizaban la unidad nacional, religiosa, racial) y heterófobos (de aversión a la diferencia) propios del antisemitismo de origen católico o fascista: los judíos eran una comunidad inasimilable que engendraba los peores males de la humanidad, como el préstamo usurario, el capitalismo y el comunismo. ${ }^{10}$ Otra forma más directa de presentarse en público puede verse en un mitin encabezado por Ezcurra Uriburu en marzo de 1962:

Pretenden mandar en esta tierra los sucios judíos de Libertad y Villa Crespo, que vinieron de los infectos ghettos y de los prostíbulos de Varsovia, de Londres y de París; Los judíos se infiltran por todas partes, pero formando una sola organización que abarca tanto la derecha como la izquierda, aunque es posible ver que mientras concurren a las universidades, los judíos son casi todos marxistas, pero cuando el padre los llama y les dice: "nene, tomá la caja di la negocie", entonces dejan de lado la revolución social y se vuelven asquerosos especuladores; los judíos tienen que ir al degüello o a la horca; los judíos no tienen ingredientes espirituales, porque en los otros ven nada más que clientes a quienes explotar (López de la Torre, 2016: 9).

En esta alocución aparecen varios estereotipos del antisemitismo clásico:el judío era poco apegado a la higiene, intelectual, corrupto, anticristiano, amante del dinero y antiproductivo. Un concierto de rasgos asociados a las clases altas y bajas, que condensaba antagonismos económicos, políticos y religioso-morales (Wieviorka, 2007: 15). Un segundo registro, a mitad de camino entre lo público y lo reservado, es la prensa del MNT. En su periódico oficial Tacuara. Vocero de la juventud nacionalista, y en el boletín interno Ofensiva, las referencias antisemitas son omnipresentes, pero no llegan a convertirse en un punto nodal de estas publicaciones. El mentado judaísmo se articulaba con el comunismo, el liberalismo y la masonería, que funcionaba como una otredad negativa y un exterior constitutivo de la propia identidad nacionalista. ${ }^{11}$ No obstante, la cuestión judía

9 CPM-DIPBA, Colección 2 “Movimiento Nacionalista Tacuara (1962-1976)”, folios 320-321.

10 En una semblanza de Cornelio Zelea Codreanu, fundador de la Guardia de Hierro, el MNT define a Rumania como "centinela de avanzada" de la civilización latina frente a los pueblos eslavos. La cuestión judía "más que cuestión de raza era un problema político en razón de que los judíos ocupaban los puestos claves de la vida nacional (...) Como todos los precursores de la idea nacional, CODREANU comprende que una doctrina sólo sentimentalmente nacionalista y simplemente antisemita, no puede saturar el vacío espiritual creado en la Nación rumana". Sin embargo, unas líneas más abajo se caracteriza al gobierno liberal rumano como "el agónico régimen montado por la judería y la masonería", CPM-DIPBA, Colección 2 "Movimiento Nacionalista Tacuara (1962-1976)", folio 303.

11 Archivo de Luis Alberto Herrán Ávila (en adelante LAHA), Parras, Adolfo, “Universidad: guarida 
tenía un peso específico: en Ofensiva se afirmaba que "el Nacionalismo abomina la componenda y ataca implacablemente a los enemigos de la Patria y de la Fe. Entre esos enemigos figuran, en primera línea, los judíos. En este aspecto el Nacionalismo posee y fomenta el espíritu de intolerancia medieval". ${ }^{12}$ En otro artículo, Pedro Otaño argumentaba: "En cuanto al antisemitismo, digamos que el mismo reposa en razones similares a las que apuntalan nuestro antimarxismo. Es decir que el judaísmo encarna aquí y allá, ahora y siempre, un cuerpo extraño, inasimilable y enemigo". ${ }^{13}$

El antisemitismo de Tacuara podía ser de inspiración religiosa, como se advierte en la crítica a un proyecto presentado en el Concilio Vaticano II para eximir a los judíos del cargo de deicidio, puesto que "el judaísmo, responsable de la muerte de Cristo, es el enemigo histórico y teológico de la Iglesia católica”. ${ }^{14}$ Este argumento se repetía en los trabajos del padre Meinvielle, quizás el principal mentor del MNT hasta la ruptura de la Guardia Restauradora Nacionalista. El antisemitismo católico de Meinvielle reivindicaba el ideal jerárquico de la sociedad medieval en clave tomista, rechazaba la modernidad y veía a los judíos como una fuerza transhistórica que había creado el materialismo, el socialismo y el liberalismo para destruir a la cristiandad (Jiménez, 2015).

Tacuara también imitaba los tópicos del antisemitismo neonazi, lo que se verifica en las notas que ponían en duda la autenticidad del diario de Ana Frank y las cámaras de gas, o definían al Holocausto como "patrañas", en base a la obra de escritores negacionistas como Paul Rassinier, para concluir que los judíos habían querido perpetrar un genocidio contra Alemania. ${ }^{15} \mathrm{El} \mathrm{MNT} \mathrm{tendió} \mathrm{algunos} \mathrm{puen-}$ tes con el nazismo, porque lo veía como parte de la misma familia de movimientos nacionalistas (Finkelstein, 2016: 150-151). Uno de los intelectuales más influyentes en la formación de los jóvenes tacuaristas fue el sociólogo y filósofo De Mahieu, un ex militante de la Acción Francesa que se radicó en la Argentina después de la caída del régimen de Vichy, envuelto en rumores sobre su participación en la División Carlomagno de las SS. La utopía comunitarista de De Mahieu criticaba tanto al marxismo como al capitalismo, y creía posible fundar empresas con roles jerárquicos pero controladas por sus propios trabajadores, ya que la burguesía era "una categoría de parásitos a eliminar" (Padrón, 2017: 160-161). Las propuestas del intelectual francés impactaron profundamente en la agrupación de Ezcurra

antinacional", Tacuara. Vocero de la juventud nacionalista, año XV, n. 9 (1960), pá. 3. Para la asociación entre judíos y comunistas en la prensa de Tacuara, v. también "Esto es un sainete", Tacuara. Vocero de la juventud nacionalista, año XIV, n. 7, 1959, p. 3; Ezcurra Uriburu, Alberto, “Carnaval de entrega” y Malm Green, Guillermo, "Universidad 'nacional'", Tacuara. Vocero de la juventud nacionalista, año XV, n. 8, 1960, pp. 1-2 y p. 3.

12 LAHA, R. V., (septiembre 1962), Una actitud equívoca, Ofensiva n. 9, pp. 6-7. Las iniciales “R.V." posiblemente eran las de Ricardo Viera, un militante de Tacuara que aparece en la misma página ofreciendo una charla sobre judaísmo. Viera participó de la ruptura del MNRT, y fue el autor intelectual del asalto al Policlínico Bancario de 1963. Años más tarde ingresó al PRT-ERP, y en 1985 fue detenido por realizar secuestros extorsivos.

13 LAHA, Otaño, Pedro, (septiembre 1962), Los jóvenes fascistas, Ofensiva n. 9, pp. 1-3.

14 LAHA, Fray Teodoro, (noviembre 1963), El Concilio y los Judíos, Tacuara. Vocero de la Juventud Nacionalista, año XVIII (s/n), p. 4.

15 LAHA, (1963), El circo pasa, Tacuara. Vocero de la juventud nacionalista, año XVIII, s/n, p. 3 y (c. 1963), El verdadero genocidio, Ofensiva s/f, p. 6. 
Uriburu no tanto por su antisemitismo, sino porque les daba un programa radical que los apartaba del nacionalismo más conservador, en tiempos donde la idea de revolución como cambio de estructuras rompía las fronteras del discurso político y se impregnaba en los medios de comunicación. No obstante, el parentesco con el nazismo se reafirmó por el impacto que provocó en el nacionalismo argentino el secuestro de Eichmann, percibido por Tacuara como una evidencia del poder de la comunidad judía en la Argentina. Tacuara realizó pintadas, brindó charlas sobre el tema donde denunció la violación del derecho internacional y estrechó vínculos con los hijos del antiguo oficial de las Waffen-SS (Bohoslavsky, 2008: 6-9). El incidente le dio una oportunidad inmejorable a la agrupación de Ezcurra Uriburu para unir en un mismo reclamo la causa del fascismo transnacional con la defensa de la soberanía argentina.

¿Qué continuidades y rupturas se operaron en el discurso sobre las razas con las migraciones de Tacuara hacia el peronismo? Un buen ejercicio es comparar dos artículos que aparecieron en noviembre de 1963, uno en Sindicato, boletín de formación del comando Mar del Plata del MNT, el otro en Barricada del nacionalismo revolucionario, una de las publicaciones del MNRT. Ambos se denominaban “¡Cuidado con la izquierda nacional!”, y uno de los dos había plagiado al otro, ya que sus contenidos eran prácticamente idénticos. Consideremos en primer lugar el texto difundido por el sector Ossorio del MNRT:

Hace tiempo que hemos podido comprobar que el comunismo, lejos de expresar una síntesis revolucionaria de las fuerzas nacidas de la conquista burguesa del poder, constituye, por el contrario, la última etapa del proceso capitalista. Las predicciones de Marx en cuanto a la concentración de los medios de producción en un número de manos cada vez más reducido no se han realizado dentro del sistema liberal, pero sí en el mundo soviético (...) De ahí la alianza automática del capitalismo individualista y del capitalismo de Estado frente a movimientos auténticamente revolucionarios (...) Es por eso que resulta cada vez más difícil para los comunistas actuar abiertamente. Nadie les da más bolilla, salvo algunos intelectualoides de décima categoría, y menos los proletarios que vivieron la época pre-revolucionaria del peronismo. Para poder actuar eficazmente, comunistas y trotzkistas tienen que disfrazar su pensamiento y sus propósitos adoptando un lenguaje nacionalista. Es esto lo que hacen, entre nosotros, los heterogéneos integrantes de la "Izquierda Nacional". El comunista Astesano, el trotzkista Ramos, el frigerista Valotta y el indefinido Hernández Arregui se proclaman peronistas y hasta rosistas y se infiltran en las organizaciones más auténticamente nacionales. ${ }^{16}$

La versión del artículo que publicó el comando marplatense del MNT replicaba línea por línea los enunciados de este texto, pero con significativos agregados y omisiones. Sindicato despotricaba contra "las predicciones del judío Marx" y la

16 LAHA, (noviembre 1963), “iCuidado con la izquierda nacional!”, Barricada del nacionalismo revolucionario n. 2, p. 2 y “iCuidado con la izquierda nacional!", Sindicato. Boletín de formación del Comando Mar del Plata del Movimiento Nacionalista Tacuara. CPM-DIPBA, Colección 2 "Movimiento Nacionalista Tacuara (1962-1976)", folio 280. Frente a la pregunta de quién robó a quién, se puede conjeturar que el original proviene del MNRT. Como Barricada del nacionalismo revolucionario mantuvo algunos tópicos antisemitas en su discurso, es razonable creer que los agregados provenían del boletín Sindicato y no al revés, ya que el sector Ossorio no hubiera tenido pruritos en emplear aquellos. 
infiltración "típicamente judaica” de la izquierda nacional. También se omitía la sentencia sobre el proletariado peronista y se agregaba un apóstrofe contra los "invertidos intelectualoides" seguidores del marxismo nacionalista. Esto pone de relieve la importancia de los tópicos antisemitas en el discurso de la Tacuara de Ezcurra Uriburu y, como veremos más adelante con mayor detalle, su progresiva marginalización en la prensa del MNRT.

Una de las mutaciones más complejas de analizar en Tacuara y sus agrupaciones derivadas es la amalgama entre antisemitismo y antisionismo, cuyos antecedentes se pueden rastrear en la indignación que provocó en diversos sectores políticos el secuestro de Eichmann. En junio de 1964, un grupo de habitantes de City Bell emitió un comunicado donde acusaban a Tacuara de pintar una svástica y la consigna "Fuera judíos" en la casa de un vecino. La particularidad era que el documento definía al MNT como una organización delictiva vinculada al nasserismo y a la República Árabe Unida. ${ }^{17}$ Los lazos entre la causa del nacionalismo panárabe y Tacuara se remontan a 1962, cuando el dirigente de la Liga Árabe Hussein Triki llegó a la Argentina para realizar una campaña de propaganda contra el Estado de Israel. Hacia 1964, en un acto para celebrar el aniversario de la Liga Árabe, militantes de la Guardia Restauradora Nacionalista y Tacuara corearon consignas antisemitas como “Fuera judíos!” y “iJudíos a la horca!” (Besoky, 2018: 12). Junto al dinero proveído por Triki para financiar sus actividades ${ }^{18}$, la apropiación derechista del antisionismo le permitía al MNT reciclar su antisemitismo, ajustándolo a banderas más legítimas de cara a la opinión pública, como el antiimperialismo y la descolonización. Del otro lado, el antisionismo y el panarabismo no hacían menos racista a Tacuara, en la medida en que los reducía a sus propias categorías culturales, como testimoniaba Baxter en la entrevista de Mundo Israelita:

\footnotetext{
Baxter dijo que no reciben ni un centavo de Nasser (...) También relató que Hussein Triki, representante de la Liga Árabe y del Frente de Liberación Nacional Argelino, les había dado conferencias. En la primera de ellas -después de haber Triki hablado en sendos actos ante los militantes de la izquierdista Federación Universitaria de Buenos Aires, y otras agrupaciones de izquierda-comenzó afirmando que la rebelión argelina era una lucha contra el fascismo francés, e insistió en su perorata de estilo antifascista que le había resultado muy útil en las anteriores conferencias. "Cuando le estábamos por romper una silla en la cabeza y ante la protesta de nuestros camaradas, Triki recapacitó y empezó a relatar sus hazañas como fascista, su participación en el asalto a la radioemisora de Argel y su lectura de proclamas fascistas, etc."19
}

El antisionismo era útil para Tacuara en la medida que se ajustara a su ideología política y sus prácticas de legitimación, de la misma manera que el nacionalismo de Triki hacía girar el amperímetro de su discurso hacia la izquierda o la derecha en función del auditorio. El antisionismo también fue un componente importante del discurso del MNA de Dardo Cabo, presentado

17 CPM-DIPBA, Colección 2 “Movimiento Nacionalista Tacuara (1962-1976)", Expediente "D” n. 218, folios n. 139-140.

18 AGR, (10 de marzo de 1964), Otra vez, atentados y crímenes políticos, Primera Plana, año 2, n. 70, pp. 6-8.

19 AGR, Zafran, Arie, (05 de mayo de 1962), "Un reportaje a los jefes de Tacuara”, Mundo Israelita. 
casi siempre de la mano de un furibundo anticomunismo. En un volante sin fecha se exigía "impedir la actuación del sionismo, que busca crear problemas ficticios y trabaja para un estado extranjero postulando la doble nacionalidad de un sector de la población". ${ }^{20}$ Este argumento se desarrolla en un fallido reportaje realizado por la revista Vea y Lea, que fue publicado posteriormente como folleto por la agrupación. Ante la pregunta "¿Qué es para ustedes el judaísmo", el MNA respondía:

Una colectividad que se ha convertido en burguesía mercantil y oligarquía financiera como forma de ejercer dominio político sobre los demás pueblos por medio del dinero. Nuestro país es hoy prueba de ello. Para ellos no hay hambre, no hay desocupación, no hay desnutrición ni analfabetismo; eso lo dejan para los hijos del país. Esa es su respuesta a la política de puertas abiertas y mano tendida con que se los recibió. A ello contestaron con una cerrada negativa a integrarse con el resto de la población, aislándose, creando sus centros, sus clubes, sus colegios, sus templos. Con el objeto de separarse de los demás como si estuvieran en territorio enemigo, y preservar así su fanatismo racial y religioso, aptitud que, favorecida por nuestro liberalismo gobernante, le permitió obtener el control de nuestras finanzas, nuestra prensa, nuestras universidades, casi diríamos de nuestro país. Todo esto es verdad aunque esté prohibido decirlo. $^{2}$

En este pasaje se repiten los tópicos del antisemitismo clásico, que ya habíamos visto en el discurso de Ezcurra Uriburu y la prensa del MNT. A pesar de todo, en los documentos del MNA se puede observar que el significante sionismo reemplaza al significante judaísmo, mucho más utilizado por la Tacuara originaria. En el periódico Nueva Argentina se señalaba que "El sionismo, junto con el capitalismo y el comunismo constituyen el trípode de enemigos del país y del justicialismo. Así lo ha reafirmado el general Perón, confirmando su estatura de visionario". ${ }^{22}$ La nota criticaba a medios gráficos como Nueva Sión, Opinión, Horizonte y La luz, por sus quejas contra el antisemitismo y su elogio de los grupos de autodefensa de la comunidad judía, que serían los auténticos responsables de "pintar esvásticas en sus sinagogas y colegios racistas". Para el MNA, los sionistas eran "enemigos de la Iglesia y de Cristo, de las Fuerzas Armadas y la Nacionalidad", razón por la cual "la propia Revolución Nacional Justicialista deberá arrasar con las fuerzas imperialistas del sionismo”. ${ }^{23}$ Si para el MNT el rechazo al Estado de Israel parecía un instrumento adecuado a la continuación del antisemitismo por otros medios, el MNA integraba la crítica del sionismo a una inflexión del discurso antiimperialista de la tercera posición marcada por el peronismo y el anticomunismo. El justicialismo del MNA, más allá de

20 Archivo de Juan Luis Besoky (en adelante AJLB), "Movimiento Nueva Argentina. Para servir a la patria" (s/f.). En el mismo volante se reclamaba liquidar la influencia comunista y sionista en el cooperativismo, "que hace que una enorme masa de dinero esté en manos de grupos extremistas extranjeros".

21 "Reportaje al MNA" (s/f), El topo blindado. Centro de documentación de las organizaciones político militares argentinas:, https://eltopoblindado.com/nacionalismo-derecha/decada-1960-nacionalismo-derecha /movimiento-nueva-argentina/reportaje-al-mna/. Las referencias al gobierno de Frondizi permiten datar al documento en 1961 o 1962.

22 AJLB, (octubre de 1965), Ultimátum para argentinos", Nueva Argentina, n. 12, p. 2.

23 AJLB, (octubre de 1965), Ultimátum para argentinos", Nueva Argentina, n. 12, p. 2. 
las afinidades electivas que tenía con la ideología de Tacuara, morigeraba el "espíritu de intolerancia medieval" del grupo de Ezcurra Uriburu. ${ }^{24}$

\section{Raza, clase y tercer mundo}

Desde su creación, el sector del MNRT que respondía a Joe Baxter y José Luis Nell tomó distancia del antisemitismo y el racismo, considerados en esta segunda instancia como desviaciones ideológicas que padecía la Tacuara originaria. En una entrevista brindada al semanario Primera Plana, Baxter sostenía que:

Nos sacamos de encima a toda la Segunda Guerra Mundial, ya no nos consideramos derrotados en la batalla de Berlín y empezamos un nuevo camino (...) Hacer antisemitismo ahora es crear un problema artificial de tipo diversionista. Divide inútilmente y crea confusión en torno del verdadero enemigo. ${ }^{25}$

A lo largo de sus editoriales en Tacuara del manchón, Baxter presentó sus ideas alrededor de los conceptos de raza, clase y tercer mundo. En el primer número de la revista, el dirigente del MNRT criticó el "viejo nacionalismo" nacido en los años treinta. Este paradigma había fracasado por replicar las ideologías nazi-fascistas en alza durante la época de entreguerras, aptas para nacionalidades maduras y grandes imperios, pero fuera de lugar en la Argentina, donde no existía una nación plenamente formada. Desde este punto de vista, el nacionalismo del MNT había negado el status colonial, puesto que "un falso orgullo les impedía ver a nuestro país en pie de igualdad con la India, el Congo o Argelia”. ${ }^{26}$ Esta espacialización simbólica, en la que los argentinos tenían más parentesco con el Tercer Mundo que con Europa, generaba una sensación de cercanía y simultaneidad entre la situación política nacional y los procesos revolucionarios de Argelia, China, Cuba y Vietnam (Gil, 2019: 199).

En Tacuara del manchón no aparecen marcas textuales de antisemitismo, un silencio en sintonía con la autocrítica que había realizado Baxter en los medios de prensa y frente a un público izquierdista en la Facultad de Filosofía y Letras de la Universidad de Buenos Aires. Sin embargo, la cuestión racial apareció entre sus páginas desde el primer número. En la editorial firmada por el principal vocero del MNRT se puede ver una definición inicial sobre el tema:

24 Las marcas textuales de racismo racialista en los documentos del MNA que pudimos relevar son escasas. En un recordatorio del fusilamiento del general Juan José Valle, la prensa de la organización describió a sus asesinos en los siguientes términos: "tienen cara de pirata, mulata y masón...y aliento pestilente de whisky inglés", v. AJLB, (noviembre 1965), Calendario heroico", Nueva Argentina, n. 13, p. 1.

25 Archivo hemerográfico del CEDINCI (CEDINCI, en adelante), (26 de septiembre de 1963), Variante: una Tacuara izquierdista", Primera Plana, n. 55..

26 LAHA, Baxter, J. J., (octubre, primera quincena, 1963), Nacionalismo, Tacuara del manchón, n. 1, p. 1. Aunque el nombre de esta publicación era Tacuara. Órgano del Movimiento Revolucionario Tacuara, preferimos la denominación con la que se hizo conocida entre la militancia política, para evitar la confusión con el periódico Tacuara. Vocero de la juventud nacionalista. 
Creemos que la realidad humana de América está constituida por el aporte de tres grandes grupos raciales, blancos, negros e indios, entre los que no existen ningún tipo de barreras. Creemos que la realidad espiritual de América está dada por el catolicismo, pero entendiendo que todas las demás minorías religiosas merecen nuestro respeto, en la medida en que no se conviertan en factor de desunión o en órganos de penetración colonial.

El pasaje revela un discurso ideológico que proclama la igualdad racial, pero no toma ninguna distancia de la tradición nacional-católica de la Tacuara originaria. Los argumentos de Baxter, más allá de escenificar a una Tacuara libre de antisemitismo, enarbolan un racismo prescindente de la jerarquización biologicista del racialismo "científico". El argumento de tolerar a las minorías religiosas mientras no se convirtieran en agentes disolventes de la nacionalidad, era concomitante a las propuestas de homogeneización cultural que discriminaban a la colectividad judía. La plataforma de la Unión Cívica Nacionalista, que había permitido al MNT presentarse a elecciones en 1962, prohibía la inmigración de "culturas no asimilables", mientras que el Programa Básico Revolucionario de Tacuara vedaba el ejercicio de la enseñanza y el proselitismo a las religiones no católicas (Gutman, 2003: 295). Por otra parte, en algunas notas de Barricada del nacionalismo revolucionario se pueden encontrar invectivas al "gorilaje judaizante", o el cuestionamiento a la Ley de enfiteusis de Bernardino Rivadavia como una maniobra "típicamente judaica”. ¿Esto quiere decir que la ideología del MNRT era una continuación del antisemitismo por otros medios? Por el contrario, al menos en lo que concierne al sector de Baxter y Nell, la mutación de Tacuara del manchón significó un pasaje de la guerra de religión a la lucha de clases.

En el artículo "Vigencia del Tercer Mundo", Baxter desarrolló con mayor amplitud sus ideas sobre raza y clase. Para el dirigente, el Tercer Mundo era una realidad política, económica y social, una cartografía de la revolución que no estaba determinada por la pertenencia racial, sino por el antagonismo entre explotadores y explotados:

En primer lugar, debemos aclarar que en ningún momento se hizo mención de un factor biológico, racial, dérmico, piloso, etc., por lo tanto, son sumamente ridículas todas las manifestaciones que hacen aparecer al tercer mundo como una elucubración de chiquilines influenciados por algún 'ideólogo' de la izquierda nacional, que llevados por una cierta mentalidad [ilegible] hacen una apología de la negritud. En cuanto al problema de la elección entre los blancos y los negros, es muy simple la definición. Entre un bello ejemplar de

27 LAHA, Baxter, J. J., (octubre, primera quincena, 1963), Nacionalismo, Tacuara del manchón, n. 1, p. 1. Aunque Baxter había renegado públicamente del antisemitismo, podía afirmar al mismo tiempo: “¿Ve?... Nadie puede decir que Fidel Castro sea antisemita. Pero es un nacionalista cubano, terminó con los explotadores, y la mayoría de los judíos se tuvo que ir”, v. "Variante: una Tacuara izquierdista”, CEDINCI, (26 de septiembre de 1963), Primera Plana, n. 55.

28 LAHA, (noviembre de 1963), Los gorilas se desnudan" (s/f), Barricada del nacionalismo revolucionario, n. 2, p. 4; L. G., (noviembre de 1963), Nuestra Revolución, Barricada, n. 2, p. 3; Laura, M., (diciembre 1963), Romper el sistema", Barricada, n. 4, p. 1. En 1965, a causa de un pedido de informes al PEN, el MNRT-Ossorio sacó un comunicado declarando “a) Su enérgica condena a la discriminación racial o religiosa. b) Su inquebrantable decisión de combatir al sionismo", CPM-DIPBA, Colección 2 "Movimiento Nacionalista Tacuara (1962-1976)", folios 329-331. 
capitalista y explotador, de cabellos rubios y lacios, de piel blanca y ojos azules y un explotado baluba, [ilegible], crespo y negro, nos quedamos con el negro, por el lado inverso si la elección se hace entre un señor Tshombe, negro, pero capitalista, explotador, verdugo de su propio pueblo y director importante de trusts internacionales y un trabajador blanco explotado por esos mismos trusts, nosotros nos quedamos con el blanco; o sea que el problema no se da entre blancos y negros sino entre explotadores y explotados, si los explotadores blancos son muchos más que los explotadores negros, no es ello motivo de orgullo para la raza blanca.

Esta parte es quizás la que mejor expresa el discurso de transición que asumió el sector Baxter-Nell del MNRT. Aun cuando el texto pretendía dejar de lado las definiciones peyorativamente racistas para clasificar las diferencias sociales según criterios de clase, continuaba racializando una parte de sus enunciados. Si para Baxter "la proporción de raza blanca en la Argentina es abrumadora, lo mismo que su origen europeo", era preciso englobar esa parcialidad en un conjunto mayor:

Nosotros sabemos también que Argentina forma parte de una nación por construir Hispano América, en la cual el aporte de otras razas es de capital importancia, y que para el desarrollo futuro de esa gran nación es imprescindible la colaboración de indios, blancos y negros (colaboración e integración que nadie, salvo algún colonialista extranjero o algún enfermo mental nativo puede poner en duda). Para nosotros la identificación con el tercer mundo no se da a través de los colores de nuestra piel sino por nuestra condición de explotados, al igual que los africanos o los asiáticos, los latinoamericanos tenemos un denominador común que es el subdesarrollo, el hambre y la opresión colonialista. ${ }^{30}$

De nuevo, aquí aparece una tensión entre categorías étnicas y clasistas. Aunque el factor determinante en última instancia era de orden socioeconómico, se seguía subrayando la cuestión racial, ya sea como un elemento residual de la subcultura política del MNT, ya sea para convencer a las bases del "viejo nacionalismo" de que la Argentina tenía un status colonial similar al de Argelia, el Congo o la India. La fusión espacial de la Argentina con el Tercer Mundo se comprueba en una nota sobre las movilizaciones del 17 de octubre de 1945, que anunciaban la irrupción política de un nuevo sujeto social:

En sus rostros y en su lenguaje se observaba su origen provinciano. Sus overoles azules marcaban el rasgo distintivo del joven proletariado criollo (...) El nacimiento del Tercer Mundo era refregado sobre las caras de los Gainza Paz, los Codovilla y los Braden. La síntesis peronista recibía la presión de la población nativa, transformadas en instrumento revolucionario por las mismas leyes imperialistas. Los nietos de las montoneras federales, bajados a la zona portuaria por la demanda de mano de obra de la incipiente industria,

29 LAHA, Baxter, J. J., (noviembre 1963), Vigencia del Tercer Mundo, Tacuara del manchón, n. 3 , p. 2. Moise Tshombe (1919-1969), fue un hombre de negocios de ideas cristianas, anticomunistas y pro-occidentales, que proclamó la independencia del efímero estado de Katanga, una provincia escindida de la República Democrática del Congo en 1960 con apoyo de Francia y Bélgica.

30 LAHA, Baxter, J. J., (noviembre 1963), Vigencia del Tercer Mundo, Tacuara del manchón, n. 3 , p. 2. 
se convirtieron en productores fabriles -herederos del Chacho, de Ferré y de Facundo-que a través de sus camisas, engrasadas por las nuevas técnicas de trabajo, transpiraban conciencia nacional.

El joven, transpirado y engrasado proletariado criollo, teñido con metáforas de lo inferior corporal como emblemas de autenticidad popular, ajeno a la docta artificialidad de las grandes urbes, sellaba un imaginario vínculo de sangre con los países de Asia, África y América Latina. Por otra parte, la analogía entre el gaucho provinciano y el obrero industrial era compartida por el sector Ossorio del MNRT:

El verdadero argentino no corrió la misma suerte que el inmigrante. Rara paradoja, el sustrato nacional era un extraño en su propia tierra (...) Es el joven proletario argentino. Es el gaucho transformado, orgulloso continuador de las montoneras. No el proletario inmigrante, importado de Europa, con qué soñaban los marxistas (...) Fue el gaucho, síntesis que tipificaba el ser nacional. Depositario y núcleo irradiante de una raza, se hallaba indisolublemente ligado a los valores religiosos. ${ }^{32}$

A diferencia de los planteos del sector de Baxter y Nell, aquí el gaucho es depositario de un ser nacional cuyos fundamentos son la raza, la cultura y la religión. La segregación nativista del inmigrante europeo, incluso el de ascendencia proletaria, también aparece en otra editorial sobre el 17 de octubre, que cita la conocida crónica de Raúl Scalabrini Ortiz sobre las movilizaciones para exigir la libertad de Perón:

Era la Patria misma, altiva, despejada, proyectada y creadora, la que revolvía la Tacuara en el esqueleto político, ideológico y económico que había montado el imperialismo. Era la voluntad de grandeza de la raza nativa, del "cabecita negra" que a través de su presencia vivificaba la sangre indomable de una Argentina poderosa.

Esta narración del 17 de octubre, como la de Tacuara del Manchón, hacía hincapié en aquel obrero nuevo y provinciano, que había sido arrancado del interior del país por la gran industria. Lo distintivo era la inclusión vindicativa de la figura del "cabecita negra", y la omisión de aquella parte del texto de Scalabrini Ortiz que daba cuenta de la heterogeneidad étnica de los manifestantes, donde "el descendiente de meridionales europeos, iba junto al rubio de trazos nórdicos y el trigueño de pelo duro en que la sangre de un indio lejano sobrevivía aún" (Scalabrini Ortiz, [1972] 2009: 11 y Grimson, 2017: 181-182). Garantizar la escisión entre el proletariado y las clases burguesas de origen inmigrante exigía un subsuelo de la patria sublevado, pero étnicamente homogéneo.

31 LAHA, (segunda quincena de octubre de 1963), Lealtad al 17 (s/f), Tacuara del manchón, n. 2 , p. 1.

32 LAHA, (octubre de 1963), iGuerra a la entrega! (s/f.), Barricada del nacionalismo revolucionario, n. 1, p. 1. Como ha señalado Ezequiel Adamovsky (2015: 31-63), el criollismo peronista ubicó al gaucho como antepasado del obrero industrial de ideas justicialistas.

33 LAHA, Alberto Redrueyo, (noviembre de 1963), Lealtad al 17, Barricada del nacionalismo revolucionario, n. 2, p. 1. La idea del obrero del interior como un sujeto social nuevo que adhería al peronismo, en oposición al proletariado de origen europeo, era similar a la caracterización del sociólogo Gino Germani, que se encontraba en las antípodas ideológicas del MNRT y el peronismo (Grimson, 2017: 171-177). 
El racismo subalternizado del MNRT-Ossorio tenía sus límites. En su esfuerzo por apartarse de lo que veía como un giro a la izquierda del sector Baxter-Nell, Barricada del nacionalismo revolucionario realizó una dura crítica al tercermundismo, con categorías racialistas que reforzaban el mito de la Argentina como nación blanca:

Últimamente se les ha dado a unos nacionalistas descubrir al "Tercer Mundo" afroasiático, en el cual ubican a Indoamérica (felicitaciones, Ramos!) y hasta a la Argentina. Se consideran solidarios de cualquier caníbal habido o por haber. Basta tener la tez oscura y el pelo crespo para recibir de ellos conmovedoras manifestaciones de amor y admiración. Nuestro país, europeo por su sangre, su cultura y su historia, se encuentra así junto con el Congo y Argelia entre los proveedores naturales de carne de cañón para las batallas de la guerra fría, tan provechosas para los dos capitalismos internacionales. ¿Cuál será el complejo de inferioridad de estos muchachos para que siempre, frente a un nacionalista blanco y un nacionalista negro se sientan atraídos por este último? ${ }^{34}$

Esta nota parece dialogar con el artículo de Baxter sobre la vigencia del Tercer Mundo, ya que ambos textos se publicaron en octubre de 1963. El sector de Ossorio defendía la doctrina de la tercera posición como un mecanismo de defensa que preservaba la distancia entre el nacionalismo y los antagonistas de la Guerra Fría, lugar desde el que intentaba disputar el sentido del tercermundismo:

"Tercera posición" tiene que ser occidental, porque, malgrado el haber usurpado esa cualidad el capitalismo, nosotros, y no ellos, representamos el sentido y la herencia de occidente. "Tercera posición" involucra el concepto de justicia social y redención de los oprimidos, porque la dignidad humana y no el colectivismo soviético ni el individualismo yanki es nuestra ambición. Por eso, además, tercera posición tendrá que ser, también, un tercer mundo. No ese "tercer mundo" que la gazmoñería sentimentaloide nos quiere endilgar. Un tercer mundo homogéneo con nuestros hermanos de raza, cultura, herencia y formación. No un tercer mundo en el cual los blancos occidentales católicos sean los idiotas útiles de la marea -muy digna y merecedora de evangélicas ayudas- de cuanto color tenga el arco iris. ${ }^{35}$

En este punto, el MNRT-Ossorio compartía el imaginario hispanista y occidentalista de buena parte del nacionalismo argentino. En una columna sobre el Día de la Raza, se señalaba que dicha fecha no podía reducirse a una celebración de "las glorias de España", ni a "sus heroicas empresas de expansión en el continente americano" ${ }^{36}$ Por el contrario, la conquista española había otorgado una identidad común a los pueblos hispanoamericanos, que se mantenía intacta a pesar

34 LAHA, M., (noviembre de 1963), iCuidado con la izquierda nacional!, Barricada del nacionalismo revolucionario, n. 2, p. 2.

35 LAHA, (diciembre de 1963), Tercera posición (s/f.), Barricada del nacionalismo revolucionario, n. 4, p. 4. El subrayado figura en el original.

36 LAHA, R.H.M. (noviembre de 1963), Vigencia de la hispanidad, Barricada del nacionalismo revolucionario, n. 2, p. 2. En otro artículo se condenaba el actual "mundo de mercachifles", y se reivindicaba en clave europeísta "la moral heroica de nuestros antepasados" que habían moldeado las guerras, desde las montoneras federales hasta la Antiguedad y las Cruzadas, v. (c. diciembre 1964), Nuestra violencia revolucionaria, Barricada del nacionalismo revolucionario, n. 8. 
de las mudanzas y las contingencias del devenir. La Castilla de la Reconquista logró "rescatar de las tinieblas geográficas y espirituales, este Nuevo Mundo, para iluminarlo con la luz de la verdad e incorporarlo a la cultura de Occidente y a la Historia universal". ${ }^{37}$ Que el antiimperialismo y el consenso antirracista de posguerra estaban a la orden del día, se puede ver por la justificación de la conquista del territorio americano. Según el autor, la expansión española no había sido una empresa colonialista en el sentido moderno del término. Para que se cumplan estos requisitos, los conquistadores tendrían que "considerarse una raza superior, rechazando a las poblaciones autóctonas hasta hacerlas desaparecer". ${ }^{38}$ Por el contrario, el concepto de raza se reñía con el principio cristiano de la igualdad humana ante Dios, que se había plasmado en las Leyes de Indias.

El MNT compartía la mirada tercerista de la América hispana como reserva moral de Occidente frente al materialismo norteamericano y el colectivismo soviético. Alberto Ezcurra Uriburu, por ejemplo, abogaba por un "occidentalismo militante", que debía posicionar a la Argentina como conductora de los destinos regionales:

En nuestra América reconocemos en los Estados Unidos una concentración de fuerzas gigantescas, pero puramente materiales (...) Los verdaderos valores de Occidente nunca podrán tener refugio allá; por eso América Latina, por su cristianismo primario, por su latinidad, es el hogar natural de aquellos valores que deben ser salvados para que se pueda salvar el mundo. En esa nuestra tierra, que tiene hombres con corazones de acero y que va desde la cuna de los aztecas hasta los hielos de la Antártida, donde se habla un mismo idioma y se reza a un mismo Dios, la Argentina se caracteriza por su substratum occidental más fuerte. Por eso queremos -y por ende creemos- que la Argentina debe ser el conductor de América Latina. Despreciamos la baba interminable sobre la hermandad de los pueblos latinoamericanos. ${ }^{39}$

El discurso del jefe de Tacuara es llamativo, porque emplea a conciencia el concepto de América Latina, que en la prensa del MNT parece intercambiable con el más revisionista de Hispanoamérica. Por otro lado, en el pasaje se establece una jerarquía entre los pueblos latinoamericanos, que se aproxima a las tendencias globales del racismo culturalista y diferencialista. Esta taxonomía es compatible con los dichos de Ezcurra Uriburu citados al comienzo de este trabajo, cuando negaba que la nación fuera una unidad biológicamente racializada. Los argentinos no constituían una raza, pero eran más occidentales que el resto de los pueblos latinoamericanos, y por esta razón tenían derecho a ejercer un liderazgo regional como primus inter pares. Si bien esta clasificación parece encontrarse a mitad de camino entre los dos paradigmas racistas más vigentes del siglo XX, el MNT también participó, de forma marginal, en la racialización positiva de las clases

37 LAHA, R.H.M. (noviembre de 1963), Vigencia de la hispanidad, Barricada del nacionalismo revolucionario, n. 2.

38 LAHA, R.H.M. (noviembre de 1963), Vigencia de la hispanidad, Barricada del nacionalismo revolucionario, n. 2 .

39 LAHA, Ezcurra Uriburu, Alberto, (1959), Nuestra zarza ardiente, Tacuara. Vocero de la juventud nacionalista, año XIV, n. 7 , pp. 1-2. Otras muestras del vínculo entre hispanoamericanismo, cristianismo y occidentalismo en (s/f, c. 1963), Del padre Castañeda, Ofensiva, p. 9; (Noviembre 1962) "Ni yankis ni marxistas, nacionalistas. Ante el conflicto del Caribe", Ofensiva, n. 11, pp. 6-7. 
subalternas. En un artículo sobre las filiaciones que unían a José de San Martín y Juan Manuel de Rosas, se señalaba con nostalgia la distancia que separaba al pasado del presente:

¿Qué hay de todo esto en la actualidad? ¿Qué hay de ese fervor nacionalista que impulsa a San Martín a transponer los Andes? ¿Qué hay de ese ardiente Nacionalismo que hace el milagro de la Vuelta de Obligado o sea el triunfo sobre las potencias de la época, cuando apenas la República Argentina era una docena de aldeas rudimentarias? ¿Qué queda de aquellos sacudimientos nacionales cuando el gauchaje enardecido ante la presencia del Caudillo, irrumpía en la Plaza de la Victoria y arrastraba tirando de las varas y de las lanzas, el carruaje del Gaucho Rubio, en un delirio multitudinario, hasta la Casa de Gobierno? (...) cuando los ejércitos defeccionaron y se convirtieron en fuerzas pretorianas, el viejo espíritu criollo fue salvado por la montonera, por el pueblo, por nuestros gauchos y mestizos, que fueron tras del Caudillo, organizándose en milicia para defender a la Patria Grande de sus eternos enemigos. ${ }^{40}$

La narrativa épica de la independencia y las guerras civiles combinaba la exaltación criollista de las clases subalternas, tipificada racialmente en la figura del gaucho y el mestizo, con el sueño de un mesías de rasgos elitistas que ya había advenido en el siglo XIX. Rosas era aquel "gaucho rubio" de ilustre prosapia y poncho baqueano, que simbolizaba la unidad nacional entre las clases altas y bajas. Con amarga añoranza, la prensa tacuarista lamentaba que los militares pretorianos del presente no estén a la altura del mito.

El MNA, como la Tacuara originaria, creía que la "Argentina por su trayectoria, su riqueza, su nivel humano y su situación geográfica es la cabeza natural de Hispanoamérica" ${ }^{41}$, posición que le confería la misión universal de unir a los pueblos de la región. Sin embargo, la agrupación de Dardo Cabo se diferenciaba de las apreciaciones de Ezcurra Uriburu por dos cuestiones: en primer lugar, el periódico Nueva Argentina oponía la idea de una América hispana unida por la historia, la cultura, y la lengua al concepto de América Latina, que asociaba a los intereses geopolíticos del Brasil, cuña utilizada por el imperialismo y la Masonería lusitana. En segundo lugar, la prensa emeneísta creía que el liderazgo argentino en el subcontinente "permitirá al Justicialismo superar la perdida base de expansión para intentar la conquista ideológica del mundo" ${ }^{42}$ Esta imagen de la Argentina potencia y la política exterior estaba en las antípodas del tercermundismo, ya que percibía la agitación marxista de los pueblos afroasiáticos como una amenaza al delicado equilibrio de la Guerra Fría:

La presencia del Asia y África modifica el cuadro de la situación y en cierto modo a la larga, también en detrimento de Rusia. En efecto, en la angustia de su dialéctica de dominación han puesto un precioso instrumento de guerra, el

40 LAHA, Laura, Mariano, (noviembre 1962), San Martín, Rosas y la soberanía, Ofensiva, n. 11, pp. 15-17. 41 AJLB, (julio 1965), Brasil. Cuña histórica de la penetración imperialista en Hispanoamérica (s/f), Nueva Argentina, n. 10, pp. 2,4.

42 AJLB, (julio 1965), Bases para una estrategia justicialista" (s/f), Nueva Argentina, n. 10, p. 2. 
marxismo, en manos de China. Esto presagia un desplazamiento de la lucha desde el campo ideológico al campo cultural y racial, al extremo que sea de temerse la inminencia del peligro amarillo que profetizara Guillermo II. ${ }^{43}$

La solución al "peligro amarillo" era la resistencia de Occidente, que debía armarse ideológicamente con la doctrina justicialista. Más allá de su identidad peronista, el MNA compartía con el MNT y el sector Ossorio del MNRT la perspectiva de que la batalla cultural entre el comunismo oriental y el auténtico occidente cristiano era más importante que la lucha de clases. Para el MNRT de Baxter y Nell, en cambio, el nacionalismo cultural de tintes hispanistas había quedado fuera de tiempo y lugar frente a la avanzada de las revoluciones anticoloniales del Tercer Mundo. Lo importante no eran las divisiones raciales o culturales, sino el antagonismo irreconciliable entre explotadores y explotados, "el color de millones de manos pidiendo el fusil". ${ }^{44} \mathrm{El}$ acercamiento de este sector al tercermundismo era parte de un movimiento cultural más amplio, que hacía hincapié en las "revoluciones de los colonizados" y reconciliaba el socialismo con la liberación nacional, con un léxico común a grupos católicos, marxistas y peronistas (Manzano, 2014: 79-104 y Georgieff, 2016: 56). Situada en este contexto, Tacuara del manchón puede ser incluida en una constelación que integraban otros periódicos y revistas como Che, Pasado y presente, Cristianismo y Revolución, y Antropología del Tercer Mundo.

\section{Consideraciones finales}

En un informe fechado el 2 de noviembre de 1973, la Dirección de Inteligencia de la Policía de la Provincia de Buenos Aires dio cuenta de una "disertación sobre marxismo en la Tacuara peronista", a la que asistieron unas cincuenta personas. ${ }^{45}$ En la charla se trataron temas como la Revolución rusa, la división entre mencheviques, bolcheviques, estalinistas y trotskistas. El orador realizó también un balance crítico de la victoria de Estados Unidos y la Unión Soviética en la Segunda Guerra Mundial, argumentando que, tras la conferencia de Yalta, las dos superpotencias se habían unido contra los regímenes nacionalistas. A pesar del contenido de la actividad, las preguntas del público giraron en torno a temas como la sinarquía, el sionismo y el judaísmo. Aunque posiblemente esta Tacuara peronista abarcara a militantes del MNT de peronización tardía, la anécdota indica que la cuestión racial gozaba de buena salud como motivo de ansiedades nacionalistas, más allá de los estallidos de violencia antisemita de comienzos de la década de 1960 .

El racismo de la Tacuara originaria estaba a mitad de camino entre el universalista-racialista (los judíos como entidad enquistada al cuerpo nacional que debía asimilarse), y el culturalista-diferencialista (la argentinidad como diferencia

43 AJLB, (julio 1965), Bases para una estrategia justicialista" (s/f), Nueva Argentina, n. 10, p. 2.

44 LAHA, Baxter, J. J., (noviembre 1963), Vigencia del Tercer Mundo, Tacuara del manchón, n. 3, p. 2.

45 “Disertación sobre marxismo en Tacuara peronista” (2/11/73) CPM-DIPBA, Colección 2 "Movimiento Nacionalista Tacuara (1962-1976)”, folio 457. 
hispánica y católica opuesta al judaísmo y al sionismo). Pensar en las particularidades del nacionalismo argentino requiere considerar que el componente religioso-cultural le otorgaba al discurso biológico un lugar modesto, ya que los procesos de etnificación discursiva estaban íntimamente ligados al concepto de nación que manejaba cada organización, y el antisemitismo católico tenía un peso mucho mayor que el racismo científico. El MNT y el MNA soñaban con una Argentina de raíces hispánicas y católicas capaz de ejercer el liderazgo regional, erigiéndose como vanguardia de Occidente en oposición al judaísmo, el sionismo, la Unión Soviética y los Estados Unidos. El sector Ossorio del MNRT compartía esta perspectiva, pero su idea de nación tenía contornos más plebeyos que le permitían reivindicar al "cabecita negra", sin que este tropo le impidiera rechazar en un lenguaje racista más o menos convencional la solidaridad con los países de Asia y África. El sector de Baxter y Nell realizó la misma operación de subalternizar la nación, pero eligió emparentar a la clase obrera peronista con la geografía rebelde del Tercer Mundo.

Los desplazamientos de la cuestión racial en Tacuara y sus agrupaciones derivadas, estaban en sintonía con las transformaciones del racismo transnacional, que descle los años 60 se apoyó en la historia y la cultura antes que en la biología (Wieviorka, 2007: 21). Puede pensarse, con razón, que las taxonomías biológicas operaron íntimamente ligadas a grillas culturales desde los tiempos de Joseph Arthur de Gobineau y su Ensayo sobre la desigualdad de las razas. En líneas generales, la díada racismo biológico/cultural no refiere a dos momentos, sino más bien a dos lógicas que pueden hibridarse (Levi-Strauss, 1999: 37-38, Wieviorka, 1994:37-48). Pero tal como advertimos en trabajos anteriores, en el tránsito entre Tacuara y sus agrupaciones derivadas se pueden encontrar huellas de una pequeña -aunque significativa- mutación del nacionalismo argentino: el pasaje de la ideología nacional-católica del MNT, caracterizada por la teología política y el racialismo, a un nacionalismo más secularizado, interesado en la emancipación económica y social del Tercer Mundo (Campos, 2016:117-134 y 2019: 124-125). La fracción del MNRT que respondía a Baxter y Nell invirtió las premisas antimaterialistas, religiosas y culturalistas que gobernaban la construcción identitaria de la Tacuara nacionalista. La crítica al racismo de este sector, aunque le otorgaba consistencia a la noción de raza, formaba parte de una cosmovisión donde lo central era el enfrentamiento de clases, y no la oposición entre culturas o fenotipos.

Las diferencias entre los discursos del MNT, el MNA y las dos vertientes del MNRT permiten suponer el tránsito de una noción trascendente de la política a otra más inmanente. Este desplazamiento, que se puede incluir en los procesos más amplios de secularización iniciados en la segunda posguerra, no significó la desaparición de la teología frente al avance de una racionalidad política instrumental, ya que el devenir de la modernidad implica la reorganización constante del trabajo de la religión en una sociedad determinada (Hervieu-Léger, 2008: 227). Algo parecido ocurrió con los procesos de etnificación discursiva: si el antisemitismo escenificaba un conflicto racial universal que sustituía al antagonismo entre explotadores y explotados, Tacuara del manchón -y en menor medida Barricada del nacionalismo revolucionario- hicieron el movimiento inverso y representaron el antagonismo 
social, asignándole un lugar central a la lucha de clases y los procesos económicos. El giro tuvo resultados dispares, pero contribuyó a desracializar un delgado filamento de la política nacionalista. En este sentido, retomando un argumento de Enzo Traverso (2014: 149), se puede matizar la idea de que el antisemitismo y el racismo son "hitos de una historia añeja y jamás interrumpida", formas de un odio siempre idéntico a sí mismo. Por el contrario, lo que se encuentra en los documentos es una trama inestable que se reconstruye una y otra vez, atravesada por mutaciones, rupturas y continuidades. El fascismo nunca es eterno. 


\section{Bibliografía}

" Adamovsky, E. (2015). El criollismo en las luchas por la definición del origen y el color del ethnos argentino, 1945-1955. Estudios Interdisciplinarios de América Latina y el Caribe, 26 (1), pp. 31-63.

" Bardini, R. (2002). Tacuara. La pólvora y la sangre. México: Océano.

" Bertonha, J. F. y Bohoslavsky, E. (2016). Circule por la derecha. Percepciones, redes y contactos entre las derechas sudamericanas, 1917-1973. Buenos Aires: Universidad Nacional de General Sarmiento.

"Besoky, J. L. (2018). Los muchachos peronistas antijudíos. A propósito del antisemitismo en el movimiento peronista. Trabajos y Comunicaciones, 47, pp. 1-29.

"Bohoslavsky, E. (2008). Contra la Patagonia judía. La familia Eichmann y los nacionalistas argentinos y chilenos frente al Plan Andinia (de 1960 a nuestros días). Cuaderno Judaico, Centro de Estudios Judaicos de la Universidad de Chile, 25, pp. 223-248.

" Campos, E. (2016). ¿De fascistas a guerrilleros? Una crítica a la historiografía de Tacuara. Tiempo Histórico, 7 (13), pp. 117-134.

"Campos, E. (2019). La prensa del Movimiento Nacionalista Revolucionario Tacuara en las mutaciones del nacionalismo argentino. Folia histórica del nordeste, 34, pp. 109-128.

" Finkelstein, F. (2016). Orígenes ideológicos de la "guerra sucia". Fascismo, populismo y dictadura en la Argentina del siglo XX. Buenos Aires: Sudamericana.

" Galvan, V. (2013). Militancia nacionalista en la era posperonista: las organizaciones Tacuara y sus vínculos con el peronismo. Nuevo Mundo Mundos Nuevos (en línea). Cuestiones del tiempo presente (consultado en línea en http://nuevomundo.revues. $\operatorname{org} / 65364,14 / 05 / 20)$.

" Gasparini, J. (2006). Manuscrito de un desaparecido en la ESMA. El libro de Jorge Caffatti. Del asalto al Policlínico Bancario por Tacuara a las FAP y el secuestro del jefe de la FIAT en París. Buenos Aires: Norma.

" Georgieff, G. (2016). Nación y revolución. Itinerarios de una controversia en Argentina (1960-1970). Buenos Aires: Prometeo.

" Gil, G. (2019). La izquierda peronista. Transitando los bordes de la revolución: 1955-1974. Buenos Aires: Prometeo.

" Gluck, M. (2012). Una batalla de una guerra imaginaria: Tacuara, el Partido Comunista y el gremialismo en el plenario sindical de febrero de 1964 en Rosario. Entrepasados, 38-39, pp. 59-73.

"Grimson, A. (2017). La homogeneización de la heterogeneidad obrera en los orígenes del peronismo. Boletín del Instituto de Historia Argentina y Americana Dr. Emilio Ravignani 47 (2), pp. 166-189.

" Gutman, D. (2003). Tacuara. Historia de la primera guerrilla urbana argentina. Buenos Aires: Vergara.

" Herrán Ávila, L. A. (2015). Las guerrillas blancas: anticomunismo transnacional e imaginarios de derechas en Argentina y México, 1954-1972. Quinto Sol, 19 (1), pp. 1-26.

" Hervieu-Léger, Danièle (2008). Vers un nuveau christianisme? Introduction à la sociologie du christianisme occidental. Paris: Les Éditions du CERF. 
" Jiménez, M. V. S. (2015). Julio Meinvielle, Tacuaras, los Tecos y El Yunque contra la «infiltración roja» en México y Argentina. Cahiers des Amériques latines, 79 (s/p).

" Lévi-Strauss, C. (1999). Raza y cultura. Madrid: Altaya.

" López de la Torre, C. F. (2016). El Movimiento Nacionalista Tacuara y la construcción del "problema judío" en la Argentina de los sesenta. Coyunturas, 1, pp. 8-24.

" López de la Torre, C. F. (2015). La violencia del Movimiento Nacionalista Tacuara contra la comunidad judía en Argentina (1955-1966). Tesis de maestría, Ciudad de México, UNAM.

" Lvovich, D. (2009). La extrema derecha en la Argentina posperonista entre la sacristía y la revolución: el caso de Tacuara. Diálogos, 13 (1), pp. 45-61.

" Manzano, V. (2014). Argentina Tercer Mundo: nueva izquierda, emociones y política revolucionaria en las décadas de 1960 y 1970. Desarrollo económico, 54 (212), pp. 79-104.

"Orlandini, J. M. (2008). Tacuara...hasta que la muerte nos separe de la lucha. Historia del Movimiento Nacionalista Tacuara, 1957-1972. Buenos Aires: Centro Editor Argentino.

" Padrón, J. M. (2012). El Movimiento Nacionalista Tacuara: expansión, organización y conflictos; el caso de la provincia de Buenos Aires, 1958-1966. Entrepasados, 38-39, pp. 37-58.

" Padrón, J. M. (2017). “iNi yanquis, ni marxistas! Nacionalistas” Nacionalismo, militancia y violencia política: el caso del Movimiento Nacionalista Tacuara en la Argentina, 19551966. Los Polvorines: Universidad Nacional de General Sarmiento.

" Patto Sá Motta, R. (2019). En guardia contra el peligro rojo El anticomunismo en Brasil (1917-1964). Los Polvorines: Universidad Nacional de General Sarmiento.

"Scalabrini Ortiz, R. (2009). Yrigoyen y Perón. Buenos Aires: Lancelot.

"Senkman, L. (1989). El antisemitismo en la Argentina. Buenos Aires: Centro Editor de América Latina.

"Senkman, L. (2001). La derecha nacionalista y los gobiernos civiles. En Rock, D. (coord.), La derecha argentina: nacionalistas, neoliberales, militares y clericales (pp. 277-283). Buenos Aires: Vergara.

"Skinner, Q. (2007). Lenguaje, política e historia. Bernal: Universidad Nacional de Quilmes.

Taguieff, P. A. (2001). El racismo. Debate feminista, 24, pp. 3-14.

" Traverso, E. (2014). El fin de la modernidad judía. Historia de un giro conservador. Buenos Aires: Fondo de Cultura Económica.

"Wieviorka, M. (1994). Racismo y exclusión. Estudios sociológicos, XII (34), pp. 37-48.

"Wieviorka, M. (2007). La mutación del racismo. Revista Mexicana de Ciencias Políticas y Sociales, XLIX (200), pp. 13-23. 